\title{
Alfabetização em contexto de pandemia: algumas ideias sobre transcriação
}

Thamara Parteka ${ }^{1}$ Elni Elisa Willms ${ }^{2}$

Submetido em: 11/12/2020

Aprovado em: 13/12/2020

DOI: $10.5965 / 23580925242020076$

1 Mestre em História (UNIOESTE-PR) e Educação (UFMT). Professora da Secretaria de Estado da Educação de Mato Grosso (SEDUC-MT). E-mail: thamaraparteka@ gmail.com.

2 Doutora em educação pela Universidade de São Paulo (FEUSP). Professora da Faculdade de Educaçã̃o da Universidade Federal de Mato Grosso (UFMT) E-mail: elnielisaw@gmail.com. 


\section{RESUMO}

Este texto, fruto de uma pesquisa acadêmica desenvolvida no Programa de Pós-graduação em Educação (PPGEDU) da Universidade Federal de Mato Grosso (UFMT), traz como ponto central a problemática da alfabetização e letramento no Brasil, práticas que têm sido alvo de debates e ataques no atual governo de Jair Bolsonaro. O trabalho evidencia, mais especificamente, a relevância acerca das implicações e reverberações de uma alfabetização desvinculada do letramento. Diante das transformações pedagógicas acarretadas pela pandemia, o texto também discute sobre a importância e o desafio de práticas lúdicas e corpóreas para o desenvolvimento de uma alfabetização e um letramento sensíveis, subsidiados pela ideia de transcriacão, conceito apresentado por Almeida e Araújo (2020).

Palavras-chave: alfabetização, letramento; transcriação.

\section{ABSTRACT}

This text, the result of academic research developed in the Graduate Program in Education (PPGEDU) of the Federal University of Mato Grosso (UFMT), brings as a central point the problem of literacy and literacy in Brazil, practices that have been the target of debates and attacks in the current Jair Bolsonaro government. The work highlights, more specifically, the relevance of the implications and reverberations of initial reading instruction unrelated to literacy. In view of the pedagogical changes brought about by the pandemic, the text also discusses the importance and challenge of playful and corporeal practices for the development of sensitive literacy and literacy, subsidized by the idea of transcription, a concept presented by Almeida and Araújo (2020).

Keywords: initial reading instruction; literacy; transcreation. 
Como não sabia falar direito, o menino balbuciava expressões complicadas, repetia as sílabas, imitava os berros dos animais, o barulho do vento, o som dos galhos que rangiam na catinga, roçando-se. Agora tinha tido a ideia de aprender uma palavra, com certeza importante porque figurava na conversa de sinhá Terta. la decorá-la e transmiti-la ao irmão e à cachorra. Baleia permaneceria indiferente, mas o irmão se admiraria, invejoso.

- Inferno, inferno.

Não acreditava que um nome tão bonito servisse para designar coisa ruim. E resolvera discutir com sinhá Vitória. Se ela houvesse dito que tinha ido ao inferno, bem. Sinhá Vitória impunha-se, autoridade visível e poderosa. Se houvesse feito menção de qualquer autoridade invisível e mais poderosa, muito bem. Mas tentara convencê-lo dando-lhe um cocorote, e isto lhe parecia absurdo.

(RAMOS, 2013, p. 8)

\section{INTRODUÇÃO}

Este texto tem a intenção de discutir o papel da alfabetização como transcriação, ou seja, a aquisição da leitura e da escrita estabelecidas de modo prazeroso, significativo, valorizando a imaginação e a transcriação de realidades criadas pelas crianças. Em meados de março de 2020 em decorrência da pandemia da Covid-19 - doença causada pelo coronavírus, denominado SARS-CoV-2 - as aulas presenciais foram suspensas nos vários estados do Brasil. Milhares de crianças, jovens e adultos bem como professores e equipes gestoras das unidades de educação dos diversos níveis de ensino, tiveram que adaptar-se muito rapidamente àquilo que passou a se chamar de ensino remoto, ou seja, tudo que antes acontecia presencialmente passou a ser mediado pelas plataformas digitais, pela necessidade de distanciamento social como maneira de mitigar a contaminação ocasionada pelo vírus. Diante desse cenário e para este texto, tomamos as contribuições da literatura como uma das formas de expressão da arte e da cultura, apresentando-se o conceito de transcriação como uma possibilidade de experimentar-se criativamente nos processos de alfabetização, mesmo diante de 
cenários desafiadores como descrito acima.

Na epígrafe que inicia este texto, o Menino mais Velho, personagem de Graciliano Ramos no livro Vidas Secas, fica impressionado ao escutar pela primeira vez a palavra inferno. Admira-se e sente desejo de apropriar-se dela, quer descobrir seu significado e desvendar o mundo por meio dela. Quando ele pergunta à mãe, Sinhá Vitória, ela diz que é algo ruim e não Ihe dá muita atenção. Ele não se conforma: como pode uma palavra tão bonita designar algo ruim?

Aproxima-se de Fabiano, seu pai, e Ihe pergunta, mas ele diz apenas: "arreda". O menino curioso, buscando conhecer, pergunta novamente à sua mãe, ela lhe diz coisas como "espetos quentes" e "fogueira". O menino quer saber mais: "- A senhora viu? Aí sinhá Vitória se zangou, achou-o insolente e aplicou-lhe um cocorote" (RAMOS, 2013, p.8).

O Menino mais Velho representa o espírito curioso das crianças e dos adolescentes que querem descobrir o mundo, fazer perguntas sobre tudo o que veem e o que escutam. A relação dos adultos com esse personagem expressa a visão adultocêntrica de mundo, a qual não considera, não vê e não respeita a criança. Não obstante, representa também a curiosidade, a crítica, a reflexão e o questionamento, pois ele simplesmente não aceita que o significado possa ser arbitrário.

O Menino mais Velho poderia até não ser alfabetizado, mas ele tinha gana pelo saber. E entendia que o conhecimento viria por meio da palavra. Quando se coloca como questionador, é reprimido e violentado. Uma leitura possível dessa obra nos leva a refletir sobre como o personagem pode representar a resistência de Graciliano Ramos e de tantas outras pessoas durante a ditadura varguista. Além do valor histórico, porém, essa e qualquer obra literária, por meio do enredo e do personagem, possibilita que realidades de outros tempos e espaços possam dialogar com ela.

Desse modo, entendemos que Vidas Secas também nos conduz a estabelecer relações com o tempo e o espaço da contemporaneidade, em que vivenciamos a gestão de governos golpistas, negacionistas, com políticas genocidas e de descaso 
para com as ciências humanas, entre elas a educação. Diz sobre a tentativa de calar o questionamento por meio da ignorância, da violência e da arbitrariedade. Desde que o nosso atual presidente, Jair Bolsonaro, assumiu o poder, vem sendo tomadas diferentes medidas para censurar assuntos que ele julga inapropriados. Para atingir a finalidade deste texto, vamos comentar o que circula por todo país como um projeto de Lei, conhecido popularmente como Lei da Mordaça ${ }^{3}$, cujo principal objetivo é proibir que os professores falem sobre temas relacionados à religião, à política e às questões de gênero e sexualidade em sala de aula. Sob a nomenclatura "escola sem partido", defendem uma suposta neutralidade da prática docente, que, sumariamente, significa a perpetuação dos valores da classe dominante e a consequente manutenção da condição de subalternidade aos oprimidos. Lembramos aqui que, para Paulo Freire, a educação é um ato político, por isso a sala de aula pode ser um espaço de debate e de pluralidade de ideias. Assim afirma o autor:

Do ponto de vista crítico, é tão impossível negar a natureza política do processo educativo quanto negar o caráter educativo do ato político. Isso não significa, porém, que a natureza política do processo educativo e o caráter educativo do ato político esgotem a compreensão daquele processo e desse ato. Isso significa ser impossível, de um lado, como já salientei, uma educação neutra, que se diga a serviço da humanidade, dos seres humanos em geral; de outro, uma prática política esvaziada de significação educativa (FREIRE, 1989, p.16).

Da mesma forma que a educação, a alfabetização é, também, um ato político. Em Vidas Secas, Sinhá Vitória traz a informação a Fabiano de que eles estão sendo enganados e explorados pelo patrão, pois o resultado das contas do pagamento difere. Ela descobre isso porque sabe contar. Fabiano confia nela, ele é um bruto, analfabeto e se envergonha dessa condição, como afirma o narrador. É nesse momento da narrativa 
que se apresenta a luta de classes: "[Fabiano] reclamou e obteve a explicação habitual: a diferença era proveniente de juros" (RAMOS, 2013, p.32). Ele percebe o embuste e a enganação a que está submetido, entretanto, por não possuir as ferramentas discursivas para afrontar o veredicto do patrão, permanece calado, e isso o mantém oprimido.

\section{QUESTÕES DESTE NOSSO TEMPO: DE SEM- PRE OU ATÉ QUANDO?}

A realidade literária apresenta um possível mundo dentro do mundo em que vivemos (BLANCHOT, 1987). Em meio a uma crise pandêmica que estamos vivendo, gerada pelo novo Coronavírus, mais que a vida das pessoas, o presidente preocupa-se exclusivamente com o mercado. Vamos citar duas, embora haja muitas e boas propostas vindas de economistas mais heterodoxos para garantir renda básica a todos, por exemplo. A Argentina ${ }^{4}$ aprovou recentemente imposto sobre grandes fortuna como forma de garantir políticas públicas para o combate aos efeitos da pandemia. E na Nova Zelândia ${ }^{5}$ um dos argumentos para o rigor no combate à pandemia é econômico: quanto mais descontrolada a pandemia, mais a economia é afetada. Então, o problema não é a preocupação econômica do presidente Bolsonaro (quem dera fosse!), mas o interesse exclusivo de continuar favorecendo economicamente quem já tem muito e que, mesmo com a pandemia, continua a enriquecer cada vez mais ${ }^{6}$.

4 Senado argentino aprova imposto sobre grandes fortunas. Disponível em $h t-$ tps://www.poder360.com.br/internacional/senado-argentino-aprova-imposto-sobre-grandes-fortunas/ Acesso em 05/12/2020.

5 As quatro medidas da Nova Zelândia para eliminar o coronavírus e reabrir a economia. Disponível em: https://neofeed.com.br/blog/home/as-quatro-medidas-da-nova-zelandia-para-eliminar-o-coronavirus-e-reabrir-a-economia/ Acesso em 09/06/2020.

6 Bilionários ficam ainda mais ricos no Brasil e no mundo durante a pandemia. Disponível em https://noticias.uol.com.br/colunas/jamil-chade/2020/10/07/ pandemia-fez-bilionarios-ficarem-ainda-mais-ricos-no-brasil-e-no-mundo.htm Acesso em 05/12/2020. 
Enquanto milhares de pessoas no mundo todo estão sendo vítimas dessa doença e tomando medidas de prevenção, cá no Brasil a preocupação do governante é com os números, com os juros, com o mercado. A situação de miséria que Fabiano e sua família enfrentam no mundo ficcional é verossimilhante a de muitos brasileiros que estão à mercê de um governo genocida e que, ao seu modo, pratica aquilo que Achille Mbembe (2016) denomina de necropolítica. Não aprofundaremos este termo neste texto, mas ele traduz a ideia do direito de eliminar ou matar determinados grupos de pessoas, ou de que algumas pessoas podem ser expostos à morte - pela falta de proteção civil, pelo descaso para com as condições dignas de vida, pela degradação de políticas públicas de atendimento à saúde, pela exclusão dos sistemas educativos e etc. - combinando-se táticas de extermínio com intimidação, segregação, amedrontamento, isolamento social, presença de milícias para garantir a "segurança", entre muitas outras formas de violência.

Nesse contexto de pandemia, brasileiros e brasileiras foram obrigados e obrigadas a voltar a trabalhar, sendo expostos e expostas à contaminação. Para o capital e para as pessoas que o defendem, é um mal necessário; afirmam que algumas pessoas não vão resistir, mas a questão não é algo natural, e sim uma questão de classe, reconhecida pelo próprio presidente de maneira extremamente perversa quando naturaliza a morte daqueles que por falta de melhores condições estruturais de vida padecerão:

$O$ vírus é igual a uma chuva. Ela vem e você vai se molhar, mas não vai morrer afogado [...] Tem essas pessoas mais fracas. Às vezes a pessoa vive pobre, fraca por natureza, dada a falta de uma alimentação mais adequada. Então essas pessoas sofrem mais (BOLSONARO, 2020).

Ou seja, no Brasil as pessoas que "podem morrer", nessa lógica genocida do presidente, são as pessoas pobres e, em geral, pretas. Para ele é natural e tanto faz se morrerem 200 mil pessoas: elas não se alimentaram adequadamente. O que ele não diz, omite e não revela é que as pessoas comeriam bem se tivessem condições dignas de vida, não houvesse uma desigualdade socioeconômica secular e estrutural no país e se o Estado provesse o mínimo 
de educação e saúde para todas as pessoas indistintamente.

Em um contexto no qual o Ministério da Saúde emite um boletim que registra 241 mortes e 6.836 casos confirmados de pessoas diagnosticadas com a COVID-197, no Brasil, o presidente defender o retorno ao trabalho por causa de uma crise econômica significa colocar o capital acima das pessoas. Do mesmo modo que o patrão não se importava se a família de Fabiano estivesse passando por necessidades, o que importava era a questão econômica.

\section{MAS POR QUE É IMPORTANTE SER ALFABE- TIZADO E LETRADO?}

Em meio à discussão aqui estabelecida, ser alfabetizado e letrado significa ter a consciência de que, em situações de crise, quem deve se responsabilizar pelo funcionamento da sociedade é o Estado. Significa lutar pelo direito de não ser cobrado por água e luz; significa ter um salário mínimo, alimentação e o direito de permanecer em casa até o momento em que uma mínima estabilidade seja reestabelecida.

Por isso, não nos espanta que, além da Lei da Mordaça, o presidente Jair Bolsonaro tenha tomado outras medidas com relação à educação no país, as quais interferem diretamente na alfabetização e no letramento. Destacamos aqui uma dessas medidas: a criação, sugerida pelo Ministro da Educação Ricardo Vélez Rodríguez, de uma Secretaria de Alfabetização, por meio do decreto Nova Política Nacional de Alfabetização, coordenada por Carlos Nadalim, em 2019, que defende o método fônico dissociado do letramento.

No método fônico defendido pelo Secretário, as crianças são levadas a repetir sons, os quais, para elas, não fazem sentido, pois não se relacionam com contexto algum. Só depois de decorar os sons, elas aprenderiam a grafia. Para Nadalim, o significado, o contexto, enfim, o letramento não deve estar associado à alfabetização, já que, para ele, o letramento:

7 Dados referentes a abril de 2020 . 
[...] nada mais é que a aplicação do construtivismo ao ensino de leitura e escrita, um conceito estritamente ideológico e político da arte de alfabetizar [...] Um dos grandes erros dessa abordagem é acreditar que as crianças podem aprender a ler e escrever por meio de um jogo psicolinguístico de adivinhações (NADALIM, 2018, transcrição áudio de entrevista).

Para ele [digamos, erroneamente], o analfabetismo funcional e os baixos índices em testes nacionais e internacionais decorrem do fato de os educadores trabalharem a alfabetização e o letramento em conjunto. Nadalim defende que a aquisição da língua escrita acontece mediante um processo que relaciona diretamente escrita e fala. Nesse sentido, para aprender a escrever, a criança precisa aprender os fonemas (menores unidades sonoras da língua) e como eles podem ser codificados (no ato da escrita) e decodificados (no ato da leitura).

Essa perspectiva é totalmente contrária aos resultados de pesquisas realizadas por Emília Ferreiro e Ana Teberosky (1985), pesquisadoras cujo entendimento é o de que a relação entre fala e escrita não é direta, pois, para elas, a aquisição da escrita não se dá por meio da fala, mas a partir do acesso à cultura letrada. Não é raro encontrarmos textos de formação educacional que reduzem a alfabetização ao deciframento do código linguístico e que defendem a perspectiva do Secretário. Porém, as autoras acima citadas, ao contrário, defendem, por meio da teoria da psicogênese, que a tarefa do alfabetizando não é aprender um código, mas apropriar-se de um sistema notacional, isto é, dominar as regras de funcionamento da ordem alfabética e compreender a alfabetização como um processo gradual (FERREIRO; TEBEROSKY, 1985).

Somam-se a essas ideias, os resultados de pesquisa de Magda Soares, que entende o alfabetizado como "aquele que apenas aprendeu a ler e a escrever, não aquele que adquiriu o estado ou a condição de quem se apropriou da leitura e da escrita" (SOARES, 1998, p. 19). A autora difere a alfabetização de letramento, considerando-o como sendo: 
[...] o estado ou condição que assume aquele que aprende a ler e escrever. Implícita nesse conceito está a ideia de que a escrita traz consequências sociais, culturais, políticas, econômicas, cognitivas, linguísticas, quer para o grupo social em que seja introduzida, quer para o indivíduo que aprenda a usá-la (SOARES, 1998, p.18).

Nesse sentido, o letramento tem seu início fora do espaço escolar e antes da alfabetização. As crianças chegam à escola com suas experiências e vivências, trazendo e expressando práticas de letramento. A alfabetização é uma tecnologia, ao passo que o letramento é um modo de ser no mundo e, segundo Magda Soares, é fundamental que ambos desenvolvam-se juntos. Por isso, a autora utiliza o termo alfaletrar para afirmar esse processo conjunto de alfabetização e de letramento.

Sobre esse processo da relação entre a palavra e o mundo, possível por meio do letramento, afirma Paulo Freire:

A leitura do mundo precede a leitura da palavra, daí que a posterior leitura desta não possa prescindir da continuidade da leitura daquele. Linguagem e realidade se prendem dinamicamente. A compreensão do texto a ser alcançada por sua leitura crítica implica a percepção das relações entre o texto e o contexto (FREIRE, 1989, p.13).

Freire compreende a relação "sujeito x mundo" como anterior à relação "sujeito x palavra", tal como se pode observar a partir do recorte que fizemos em Vidas Secas sobre a consciência que Fabiano tem de ser explorado pelo patrão. É a compreensão que se tem do mundo e das relações estabelecidas em determinado grupo social que conduzirá a maneira pela qual o sujeito interpretará sua realidade, pois a construção de sentido e de significado é coletiva. Para ele, a educação deve ser libertadora, trazendo consciência para o aprendiz sobre a realidade em que vive.

A partir dessas reflexões, são compreensíveis as medidas adotadas pelo atual governo e os posicionamentos divergentes do Secretário de Educação diante da perspectiva freiriana, pois as classes privilegiadas tendem a não querer uma educação crí- 
tica e libertadora, ao contrário, querem uma educação predominantemente alienante. Por isso defendem um modelo de alfabetização desvinculada do letramento e um ensino por meio de cartilhas ${ }^{8}$ : não querem que o sujeito desenvolva as habilidades de reflexão e de interpretação, nem que tenha uma formação crítica e, portanto, transformadora da realidade.

Além de uma alfabetização política e contextualizada, vinculada ao letramento e à realidade social da criança, compreendemos que seja necessária uma alfabetização voltada para o desenvolvimento do ser humano de maneira integral ${ }^{9}$, considerando os aspectos físicos, vitais e emocionais.

Nesse sentido, é de suma importância que a criança tenha vivências corpóreas, ou seja, a oportunidade de experimentar a natureza com o seu próprio corpo. É por meio da experiência corpórea e do saber sobre essa experiência que a criança conhece o mundo, é por meio do brincar que ela investiga o funcionamento das coisas. Por isso, um dos melhores incentivos que pais, mães, educadores jardineiros e jardineiras podem fazer é possibilitar essa experiência. Mas, de que trata essa experiência? Jorge Bondía afirma:

80 presidente Jair Bolsonaro utilizou a Cartilha Caminho Suave e fez a defesa do seu uso para a alfabetização, criticando os livros didáticos atuais por trazerem muito conteúdo escrito. GUIMARÃES, Lígia. O que é a cartilha Caminho Suave, que alfabetizou milhões e caiu em desuso, mas mantém fãs como Bolsonaro. Jornal BBC News. 13/01/20. Disponível: https://www.bbc.com/portuguese/brasil-51070840. Acesso: 19/03/2020.

9 Naturalmente não podemos educar ou lecionar se, ao fazê-lo, de certo modo não formos capazes de captar em espírito o ser humano global. - pois na época do desenvolvimento da criança, esse ser humano global é muito mais importante do que mais tarde. Como sabemos, esse ser humano global inclui o eu, o corpo astral, o corpo etéreo e o corpo físico. (STEINER, 1995, p. 5). 


\begin{abstract}
A palavra experiência vem do latim experiri, provar (experimentar). A experiência é em primeiro lugar um encontro ou uma relação com algo que se experimenta, que se prova. O radical é periri, que se encontra também em periculum, perigo. A raiz indo-européia é per, com a qual se relaciona antes de tudo a idéia [sic] de travessia, e secundariamente a idéia [sic] de prova. [...] O sujeito da experiência tem algo desse ser fascinante que se expõe atravessando um espaço indeterminado e perigoso, pondo-se nele à prova e buscando nele sua oportunidade, sua ocasião (BONDíA, 2002 , p. 25 , grifos do autor).
\end{abstract}

A experiência do brincar acontece por meio das interações que as crianças estabelecem entre si e com o que as circunda, deixando marcas topográficas que as constituem como seres humanos. É por meio da brincadeira e do "faz de conta" que as crianças apreendem o mundo, por imitação: de si, das outras crianças, dos adultos, dos animais, dos objetos. Não se trata de uma mera cópia, mas de uma imitação criadora, pois se constitui a partir de uma atividade interpretativa e expressiva. A brincadeira, por assim dizer, exige conhecimento e imaginação (ANTÔNIO; TAVARES, 2013).

Segundo W. Luijpen, citado por Duarte Júnior, há uma sabedoria no corpo, sendo, por meio dele, um dos modos de conhecer e se relacionar com o mundo:

Meu corpo 'sabe' melhor que eu o que significam duro, mole, agudo, viscoso, frio, quente, pesado, doloroso, saboroso etc. As pernas de um grande futebolista, ou antes, todo o seu corpo, 'sabe' muito mais acerca do campo, da bola, do gol, dos companheiros, do espaço e do tempo que o próprio jogador. Enquanto pode confiar nesse misterioso 'saber' é um excelente futebolista. Assim que começa a 'refletir', está no momento de pensar em ser técnico. Meus pés 'conhecem' muito melhor do que eu pessoalmente as escadas que todo dia subo e desço, e meu corpo 'sabe' muito mais que eu a respeito de minha bicicleta. (...) 'Sob' o sujeito pessoal há, pois, em ação um sujeito pré-pessoal. Esse sujeito pré-pessoal, quase se diria 'anônimo', é o corpo humano... (LUIJPEN, 1973, apud DUARTE JR., 2004, p.130). 
A sabedoria do corpo da criança que explora o mundo para dele apropriar-se em todas as suas camadas e por meio de todos os seus sentidos pode também nos conduzir para o campo da literatura, algo que discutimos na próxima seção.

\section{FINALIZANDO: A LITERATURA COMO ARTE E TRANSCRIAÇÃO}

Uma narrativa, uma pintura, uma música, enfim, uma obra de arte pode afetar a criança, a partir das imagens e dos símbolos nelas contidos, pode ser um potencializador no processo de escrita por meio da transcriação. Partimos desse conceito abordado por Rogério de Almeida e Alberto Filipe de Araújo $(2020$, p.6):

A transcriação é compreendida como um processo dinâmico que envolve elementos presentes no engendramento, na elaboração de uma obra de arte e em sua recepção pelos apreciadores, que operam como coautores dos sentidos das obras. [...] podemos entender a transcriação como uma "transposição criativa" (JAKOBSON apud CAMPOS, 1969, p. 110), já que não se trata da reconstituição da mensagem, mas "do sistema de signos em que está incorporada esta mensagem, da informação estética, não da informação meramente semântica" (CAMPOS, 1969, p. 100). A tradução não se restringe, entretanto, a meros processos de câmbio linguístico[...].

Nesse processo, novos sentidos construídos possibilitam, inclusive, que o leitor saia do papel de leitor e se torne também escritor. Ele pode criar, alterar, aumentar, diversificar a narrativa. Ele pode partir de uma lenda amazônica e misturar elementos de seu cotidiano, como apresenta Parteka (2020) em sua dissertação de mestrado. Por meio da literatura, é possível criar novos mundos dentro do mundo. Trata-se da potência de transcriação.

Cavalcanti (1997) propõe que os docentes façam da literatura um jogo e, que por meio dela, criem desafios a partir da 
escrita. Por exemplo, pode-se solicitar que as crianças narrem o início da história e em seguida pedir para criarem um final; pode-se dar palavras-chave para que construam uma narrativa; pode-se pedir que descrevam um personagem da maneira mais horripilante que conseguirem, enfim, as possibilidades criativas são infinitas. Dessa forma aprender torna-se uma brincadeira, algo que provoca as crianças, que as coloca no lugar de protagonistas.

Da mesma forma, por meio do brincar livre, as crianças encaram seus limites, seus medos e é por meio das brincadeiras que elas conseguem ultrapassá-los, tal como faz o poeta quando em estado de poesia:

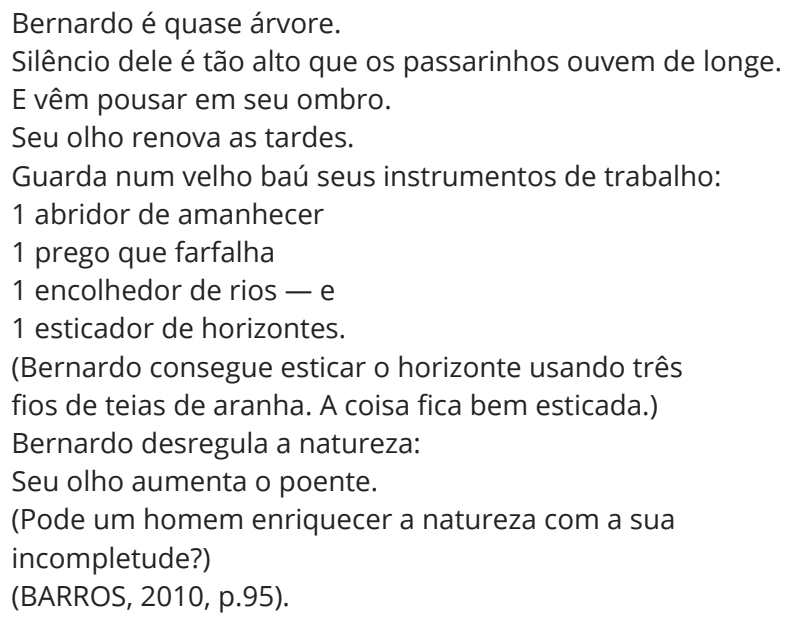

O eu-lírico do poema acima afirma que o menino desregula a natureza. Bernardo faz peraltagem com as palavras! Por meio da criação poética podemos compreender melhor o que também é próprio do brincar livre, quando a criança tem contato com aquilo que é mais natural. Assim ela se sente peralta e criadora, livre e com autonomia para ser o que quiser, como o poeta acima, que guarda coisas consideradas inúteis como se fossem instrumentos de trabalho. Nesse sentido, Steiner (1995) 
recomenda que os brinquedos sejam criados a partir daquilo que é natural: galhos, madeiras, cascas, sementes, seda, algodão, pois, se a criança é extensão da natureza, quanto maior o contato com a natureza, mais contato ela tem consigo própria. Em algumas escolas, como a Waldorf, opta-se por brinquedos criados pelas próprias crianças com o menor número de informações possíveis, dado que, quanto menos informação, mais ela tem espaço para a criação.

Desse modo, entendemos que as investigações, os desafios, as descobertas e as experiências corpóreas por meio das quais a criança sente e percebe, despertadas em sua interação com a natureza da forma mais plural, permitem que ela tenha subsídios para reconhecer intelectualmente as experiências corpóreas já adquiridas, as quais são uma condição sine quo non para o desenvolvimento saudável da alfabetização ${ }^{10}$.

Uma educação dedicada ao desenvolvimento saudável e natural da criança não criará um jardim de infância que simule a realidade da escola - com grama artificial, playground, ferramentas e brinquedos apenas de plástico, por exemplo -, um sistema "pré-escolar" em que as crianças precisam aprender, apenas por meio da razão - ou do decorar -, as primeiras letras alfabéticas, números, atividades positivistas de cortar e pontilhar e apenas reproduzir algo dado. Mas fará o possível para que ela tenha as mais diferentes experiências que permitam conhecer os seus sentidos, os seus ritmos, a si mesma e a natureza. Transcriar, enfim.

Por meio do contato com os elementos da natureza e com as investigações de si e do mundo desenvolvidas durante o brincar é que a criança forma um arcabouço de conhecimentos, de sensibilidades e de experiências que lhe permitem adquirir os

10 Por desenvolvimento saudável da alfabetização entendemos as práticas que respeitem a criança em sua dimensão corpórea e psíquica. Não é possível uma criança fazer o movimento de pinça, reconhecer o lado direito e esquerdo, em cima, embaixo etc., se ela não desenvolveu isso corporalmente. Quando se exige isso intelectualmente, sem ter desenvolvido sua habilidade corpórea, a criança se sentirá mutilada e terá dificuldades de obter êxito, uma vez que uma etapa do desenvolvimento fora ignorada. 
subsídios necessários para a alfabetização. É por meio do real percebido e das lembranças do real vivido que a criança pode criar, imaginar e pensar.

Nesse mesmo sentido, os educadores Severino Antônio e Katia Tavares (2013, p.19) defendem: "O sentimento é tão importante quanto o raciocínio. Não deveríamos dissociar o sensitivo e o intelectivo, fazer abismos entre o sentir e o pensar. A criança sente e pensa inseparavelmente". Por isso ela é criativa. Por isso é capaz de ultrapassar as barreiras que nós adultos criamos entre razão e sensibilidade. Por isso é capaz de fazer outras e maiores perguntas, por isso liberta-se das amarras do já pensado. E a alfabetização, nessa perspectiva, pode tornar-se a arte de criar a si mesmo na relação com os outros e com o mundo que nos circunda.

\section{REFERÊNCIAS}

ALMEIDA, Rogério; ARAÚJO, Alberto. A transcriação do mundo pela experiência: esboço para uma educação estética. In: EccoS - Revista Científica, São Paulo, n. 53, p. 1-18, e16676, abr./jun. 2020.

ANTÔNIO, Severino; TAVARES, Katia. A Poética da Infância: Conversas com quem educa as crianças. São Paulo. Editora Passarinho, 2019

BARROS, Manoel. Poesia completa. São Paulo: Leya, 2010.

BLANCHOT, Maurice. O espaço literário. Rio de Janeiro: Rocco, 1987.

BOLSONARO, Jair. Entrevista. In: ADLER, Matheus. Bolsonaro sobre coronavírus: 'É igual chuva: você vai se molhar, mas não vai morrer afogado. 01/04/20. Estado de Minas Disponível em: https://www.em.com.br/app/noticia/politica/2020/04/01/ interna_politica,1134792/bolsonaro-sobre-coronavirus-e-igualchuva-voce-vai-se-molhar-mas-n.shtml. Acesso: 02/04/2020. 
BONDÍA, Jorge L. Notas sobre a experiência e o saber de experiência. Revista Brasileira de Educação Jan/Fev/Mar/Abr 2002, № 19.

CAVALCANTI, Zélia (coord.) Alfabetizando. Porto Alegre: Artes Médicas 4, 1997.

DUARTEJR., J. F. O sentido dos sentidos: a educação (do) sensível. O Saber Sensível (Estesia). Criar Edições, 3 ed., PR, 2004.

FERREIRO, Emilia; Teberosk, Ana. A Psicogênese da Língua Escrita. Porto Alegre: Artes Medicas 1985. 284p.

FREIRE, Paulo. A importância do ato de ler. São Paulo: autores associados. Cortez, 1989.

MBEMBE, Achille. Necropolítica. Arte \& Ensaios. Revista do ppgav/eba/ufrj. n. 32. dezembro 2016. p. 122-151. Disponível em https://revistas.ufrj.br/index.php/ae/article/view/8993/7169 Acesso em 14/05/2020.

NADALIM, Carlos. Letramento, o vilão da alfabetização no Brasil. 12 de maio de 2018. Disponível em: https://www.youtube. com/watch?v=_9JEhWtIRKg. Acesso em: 17/03/20.

PARTEKA, Thamara. Sociedades dos amores: histórias de uma turma em alfabetização e uma alfabetizadora em devir. Dissertação de Mestrado. Programa de Pós-Graduação em Educação (PPGEdu). Universidade Federal de Mato Grosso. Rondonópolis, 2020.

RAMOS, Graciliano. Vidas secas. [107] Rio de Janeiro: Record, 2013.

STEINER, Rudolf. Verdade e ciência: prelúdio à uma Filosofia da Liberdade. São Paulo: Editora Antroposófica, 1995.

SOARES, Magda. Letramento: um tema em três gêneros. 2 ed. Belo Horizonte: Autêntica, 1998. 